\title{
Prevalence and Determinant Factors of Chronic Calculous Cholecystitis among Senile Population Arar, KSA
}

Maha Mukhlef R Alanazi ${ }^{1}$, Abdalla Mohamed Bakr Ali ${ }^{2}$, Waad Salamah Alaleimi ${ }^{1}$, Asem Matrouk Z Alrowaili ${ }^{1}$, Sultan Majed M Alshammari ${ }^{1}$, Saud Rteamy R Alanazi ${ }^{1}$, Abrar Asaad M Alanazi ${ }^{1}$, Waad Alazri S Alanazi ${ }^{1}$, Jawaher Naif M Althayidi ${ }^{1}$, Alaa Ali S Alanazi ${ }^{1}$, Zain Amer L Alruwily ${ }^{1}$, Dnya Saleh Affat Alanaziy ${ }^{1}$, Zaid Qati F Alshammari ${ }^{1}$, Mashail Rasheed M Alshammari ${ }^{1}$, Fatimah Awadh A Alrasheedi ${ }^{1}$

${ }^{1}$ Faculty of Medicine, Northern Border University, KSA, ${ }^{2}$ Faculty of Medicine, Sohag University, Egypt *Corresponding Author: Maha Mukhlef R Alanazi, E-mail: apdo3332008@gmail.com

\begin{abstract}
Background: chronic calculous cholecystitis is an inflammatory disease which affects the gallbladder wall and causes motoric-tonic dysfunctions of the biliary system accompanied by gallstones in the lumen of the gallbladder and biliary pain. Among aging study groups, the prevalence of gallstone disease is likely to increase.

Aim of the Work: to determine the prevalence and determinant factors of chronic calculous cholecystitis among senile population in Arar, KSA.

Patients and Methods: the present cross sectional community based study was conducted in Arar city, Northern Border Province, KSA on 217 adult people aged 50 years and more. Data were collected through personal interviews with the study population and filling the questionnaire which guided us to the data of socio-demographic status, smoking, chronic diseases, already previously diagnosed with chronic calculous cholecystitis, after ensuring the diagnosis by reviewing the accompanied health reports and/or prescriptions and asking the accompanied caregivers about the case.

Results: the mean age of the participants $( \pm$ SD) was $69.9( \pm 9.3)$ years; male to female ratio was 43.8 to 56.2. The overall prevalence rate of chronic calculus cholecystitis found in this study was $6.9 \%$. There was a relationship between chronic calculus cholecystitis and age group, sex, DM, BMI group, Thyroid disease and Hypertension. The prevalence of chronic calculus cholecystitis was more in females compared to males $(9.0 \%$ vs. $4.2 \%)$.

Conclusion: female gender, diabetes and obesity are significantly associated factors in the development of gallstones. Thus, understanding the gallstones pathogenesis would result in life style modifications and weight loss which would decrease the rates of the disease.
\end{abstract}

Keywords: Chronic Calculous Cholecystitis, Prevalence, Determinants, Senile Population, Arar, KSA

\section{INTRODUCTION}

Calculous cholecystitis is a hepato-biliary system disease caused by cholesterol and/or bilirubin metabolic disorder. It is characterized by the formation of gallbladder and/or biliary tract stones ${ }^{[1]}$. It is the most common type of cholecystitis as gallstones are highly prevalent, but most $(80 \%)$ are asymptomatic ${ }^{[2]}$. Gallstones prevalence is associated with geographical and ethnic variations ${ }^{[3]}$. In the study of Bateson ${ }^{[4]}$, it was estimated that up to $28 \%$ and $42 \%$ of senile British men and women, respectively, aged 80-89 years have gallstones. Of these, $30 \%$ are symptomatic, and are seen by surgeons around the country ${ }^{[4]}$. However, it is less prevalent in China, Japan and Egypt, compared to Western communities ${ }^{[5,6,7]}$. In Saudi Arabia, gallstones prevalence is not well defined, and more studies need to be done throughout the country. However, recent studies indicated high prevalence and incidence ${ }^{[8]}$. The chronic type of calculous cholecystitis affects the gallbladder wall and causes motoric-tonic dysfunctions of the biliary system, accompanied by presence of gallstones in the gallbladder lumen, and reveals as biliary pain ${ }^{[9]}$. The risk of developing gallstone disease and its complications increases with age. Among aging study groups, the prevalence of gallstone disease is more likely to increase. The health of the gallstone patients is improving secondary to the improvement of the diagnostic and therapeutic technologies ${ }^{[10]}$. In the study of González et al. who thought that the different therapeutic methods that are at present in use, should be applied to this group, and whether surgical or longterm medical treatment should be applied, it was found that elderly patients can undergo surgery in selected cases with an acceptable mortality rate and high morbidity. Surgery is recommended with those of a lesser age, not always possible as many of them lacked prior symptoms ${ }^{[11]}$. As this field is not well studied in Northern Saudi Arabia, this study was carried aiming at determining the prevalence and determinant factors of chronic calculus cholecystitis among elderly in Arar city, the capital of the Northern area of Saudi Arabia. 


\section{AIM OF THE WORK}

To determine the prevalence and determinant factors of chronic calculous cholecystitis among senile population in Arar, KSA.

\section{PATIENTS AND METHODS}

The present cross sectional community based study was conducted in Arar city, the capital of Northern Borders Governorate on 217 adult people of age 50 years and more. The sample size was calculated using the sample size equation: $n=z 2 p(1-p) / e 2$, considering target population more than 1000 , and study power $95 \%$. Systematic random sampling technique was followed. After identifying the first house randomly in the selected area, every 9th house was visited to include all the adult subjects residing in those selected houses till the required sample is covered. Data were collected through personal interviews with the sampled population and filling the questionnaire which guided us to the data of the sociodemographic characteristics such as age, sex, educational status and marital status, it also included smoking status and certain chronic diseases that may be prevalent among adults suggested to affect the gall bladder such as obesity, hypertension, diabetes millets and hyperlipidemia. The questionnaire included also questions regarding the already previously diagnosed chronic calculus cholecystitis and their determinants, after ensuring the diagnosis by reviewing the accompanied health records and prescriptions and asking the accompanied caregivers about the case. Ethical considerations: Data collector gave a brief introduction to the participants by explaining the aims and benefits of the study. Official Esthetical approval to carry out this study was obtained from the health directorate in Arar city. Informed written consent was obtained from all participants. Anonymity and confidentiality of data were maintained throughout the study. There was no conflict of interest. Statistical analysis: We utilized the statistical package for social sciences, version 16 (SPSS Inc., Chicago, Illinois, USA) to analyze the study data. The results were displayed as counts and percentages. The $\mathrm{X} 2$ test was used as a test of significance, and differences were considered significant at $P$ value less than 0.05 .

\section{RESULTS}

Table (1) illustrates the sociodemographic characteristics and BMI status of the studied elderly population. The table showed that mean age $( \pm \mathrm{SD})$ was $69.9( \pm 9.3)$ years, male to female ratio was 43.8 to 56.2 , married were 61.3 while 35.5 were widow, illiteracy constitutes $51.6 \%$, primary school literates were $18.9 \%$. As regards working, $15.3 \%$ were shepherd, $64.2 \%$ were not working and $20.5 \%$ were retired. Figure (1) shows the percentage distribution of chronic calculus cholecystitis among the elderly population. The overall prevalence rate of chronic calculus cholecystitis found in this study was $6.9 \%$. Table (2) demonstrates the prevalence of chronic calculus cholecystitis and other related chronic diseases among the studied population. Hypertension was found in $44.9 \%$, Myocardial infarction in $11.6 \%$, hypothyroidism in $12.3 \%$, diabetes $37.0 \%$, diabetic nephropathy in $5.8 \%$ and renal insufficiency in $6.5 \%$. As regards the BMI, about half (45.7\%) were obese, $26.8 \%$ overweight and only $24.6 \%$ had normal weight. Table (3) shows the relationship between Chronic calculus cholecystitis and age group, sex, DM, BMI group, Thyroid disease and Hypertension in the studied elderly population. All of gallstones affected the participants aged 60-70 years old. The female gender showed insignificant association with gallstones where $9.0 \%$ of females suffered from gallstones compared to $4.2 \%$ of males. Gallstones prevalence was $10.1 \%$ in obese, $5.4 \%$ in overweight, $3.6 \%$ in normal and $0 \%$ in underweight. BMI group, Diabetes Mellitus and Hypertension showed significant association with prevalence of gallstones $(\mathrm{P}<0.05)$. Thyroid disease and Smoking showed nonsignificant association with prevalence of gallstones.

Table (1): Socio-demographic characteristics and smoking among the studied elderly, Arar, 2017 $(\mathrm{N}=238)$

\begin{tabular}{|c|c|c|}
\hline Variables & Frequency (No.) & Percent (\%) \\
\hline Age group & & \\
\hline $60-$ & 141 & 65.0 \\
\hline $70-$ & 56 & 25.8 \\
\hline $80+$ & 20 & 9.2 \\
\hline Mean age $( \pm \mathrm{SD})$ & \multicolumn{2}{|c|}{$69.9 \pm 9.3$} \\
\hline \multicolumn{3}{|l|}{ Sex } \\
\hline Female & 122 & 56.2 \\
\hline Male & 95 & 43.8 \\
\hline \multicolumn{3}{|l|}{ Education } \\
\hline Illiterate & 112 & 51.6 \\
\hline Primary & 41 & 18.9 \\
\hline Secondary & 19 & 8.8 \\
\hline University or more & 29 & 13.4 \\
\hline Preparatory & 16 & 7.4 \\
\hline \multicolumn{3}{|l|}{ Working status } \\
\hline Shepherd & 35 & 15.3 \\
\hline No work & 147 & 64.2 \\
\hline Retired & 47 & 20.5 \\
\hline \multicolumn{3}{|l|}{ Marital status } \\
\hline Widow & 77 & 35.5 \\
\hline Single & 3 & 1.4 \\
\hline Married & 133 & 61.3 \\
\hline Divorced & 4 & 1.8 \\
\hline
\end{tabular}




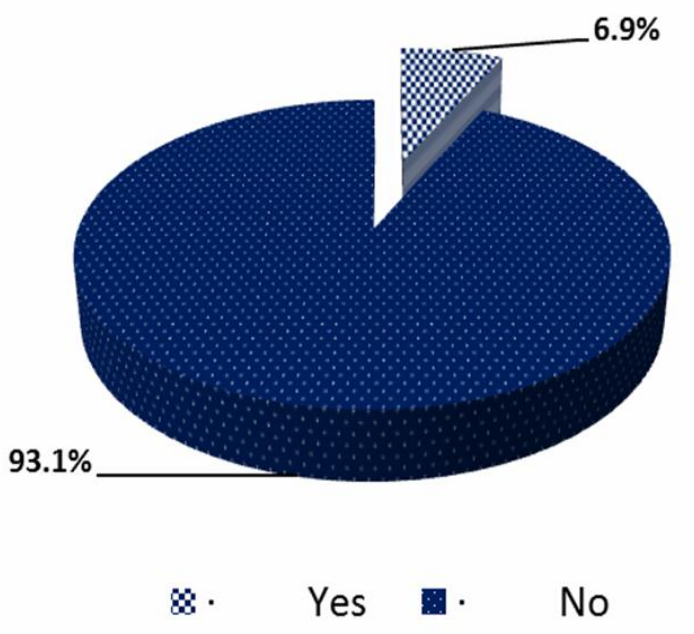

Figure (1): Prevalence of chronic calculus choleyctisis among elderly population in Arar city, Northern Saudi Arabia, 2017.

Table (2): Prevalence of Chronic calculus cholecystitis and other related chronic diseases among the studied elderly population, Arar, 2017 $(\mathrm{N}=229)$

\begin{tabular}{|c|c|c|}
\hline Chronic calculus cholecystitis & No. & $\%$ \\
\hline Yes & 15 & 6.9 \\
\hline No & 202 & 93.1 \\
\hline \multicolumn{3}{|l|}{ Cardiovascular diseases } \\
\hline Hypertension & 108 & 49.8 \\
\hline Ischemic heart diseases & 37 & 17.1 \\
\hline Previous myocardial infarction & 24 & 10.1 \\
\hline \multicolumn{3}{|l|}{ Thyroid diseases } \\
\hline Hyperthyroidism & 12 & 5.5 \\
\hline Hypothyroidism & 26 & 12.0 \\
\hline \multicolumn{3}{|l|}{ Diabetes } \\
\hline Yes & 89 & 41.0 \\
\hline No & 128 & 58.9 \\
\hline \multicolumn{3}{|l|}{ Renal problems } \\
\hline Diabetic nephropathy & 11 & 5.1 \\
\hline Renal insufficiency & 15 & 6.9 \\
\hline Chronic renal failure & 2 & .9 \\
\hline \multicolumn{3}{|l|}{ Body Mass Index (kg/m2) status } \\
\hline Underweight & 7 & 3.2 \\
\hline Normal & 55 & 25.3 \\
\hline Overweight & 56 & 25.8 \\
\hline Obese & 99 & 45.6 \\
\hline \multicolumn{3}{|c|}{$\begin{array}{c}\text { Mean BMI }( \pm \text { SD }) \\
29.9 \pm 9.4\end{array}$} \\
\hline \multicolumn{3}{|l|}{ Smoking } \\
\hline Ex-Smoker & 150 & 69.1 \\
\hline Smokers & 16 & 7.4 \\
\hline Non smoker & 51 & 23.5 \\
\hline
\end{tabular}

Table (3): The relationship between Chronic calculus cholecystitis and age group, sex, DM, BMI group, Thyroid disease and Hypertension in the studied elderly population, Arar, 2017

\begin{tabular}{|c|c|c|c|c|}
\hline \multirow[b]{2}{*}{ Variables } & \multicolumn{2}{|c|}{$\begin{array}{c}\text { Chronic calculus } \\
\text { cholecystitis }\end{array}$} & \multirow{2}{*}{$\begin{array}{c}\text { Total } \\
(\mathrm{N}=229 \\
)\end{array}$} & \multirow{2}{*}{$\begin{array}{c}\mathbf{P} \\
\text { valu } \\
\mathbf{e}\end{array}$} \\
\hline & $\begin{array}{c}\text { Yes } \\
\left(\begin{array}{c}N=65 \\
)\end{array}\right.\end{array}$ & $\begin{array}{c}\text { No } \\
(\mathrm{N}=173 \\
)\end{array}$ & & \\
\hline \multicolumn{5}{|l|}{ Age group } \\
\hline \multirow{2}{*}{$60-$} & 15 & 126 & 141 & \multirow{6}{*}{$\begin{array}{c}0.01 \\
3\end{array}$} \\
\hline & $10.6 \%$ & $89.4 \%$ & $100.0 \%$ & \\
\hline \multirow{2}{*}{$70-$} & 0 & 56 & 56 & \\
\hline & $.0 \%$ & $100.0 \%$ & $100.0 \%$ & \\
\hline \multirow{2}{*}{$80+$} & 0 & 20 & 20 & \\
\hline & $.0 \%$ & $100.0 \%$ & $100.0 \%$ & \\
\hline \multicolumn{5}{|l|}{ Sex } \\
\hline \multirow{2}{*}{ Female } & 11 & 111 & 122 & \multirow{4}{*}{$\begin{array}{c}0.13 \\
2\end{array}$} \\
\hline & $9.0 \%$ & $91.0 \%$ & $100.0 \%$ & \\
\hline \multirow{2}{*}{ Male } & 4 & 91 & 95 & \\
\hline & $4.2 \%$ & $95.8 \%$ & $100.0 \%$ & \\
\hline \multicolumn{5}{|c|}{ Diabetes Mellitus } \\
\hline \multirow{2}{*}{ Yes } & 13 & 76 & 89 & \multirow{4}{*}{$\begin{array}{c}0.00 \\
1\end{array}$} \\
\hline & $14.6 \%$ & $85.4 \%$ & $100.0 \%$ & \\
\hline \multirow{2}{*}{ No } & 2 & 126 & 128 & \\
\hline & $1.9 \%$ & $98.1 \%$ & $100.0 \%$ & \\
\hline \multicolumn{5}{|l|}{ Thyroid disease } \\
\hline \multirow{2}{*}{$\begin{array}{l}\text { Hyperthyroidis } \\
\mathrm{m}\end{array}$} & 0 & 12 & 12 & \multirow{6}{*}{$\begin{array}{c}0.18 \\
1\end{array}$} \\
\hline & $.0 \%$ & $100.0 \%$ & $100.0 \%$ & \\
\hline \multirow{2}{*}{ Hypothyroidism } & 0 & 26 & 26 & \\
\hline & $.0 \%$ & $100.0 \%$ & $100.0 \%$ & \\
\hline \multirow{2}{*}{$\begin{array}{l}\text { No thyroid } \\
\text { disease }\end{array}$} & 15 & 164 & 179 & \\
\hline & $8.4 \%$ & $91.6 \%$ & $100.0 \%$ & \\
\hline \multicolumn{5}{|l|}{ BMI group } \\
\hline \multirow{2}{*}{ Underweight } & 0 & 7 & 7 & \\
\hline & $.0 \%$ & $100.0 \%$ & $100.0 \%$ & \\
\hline & 2 & 53 & 55 & \\
\hline Normal & $3.6 \%$ & $96.4 \%$ & $100.0 \%$ & 0.03 \\
\hline Overweight & 3 & 53 & 56 & 6 \\
\hline Uverweignt & $5.4 \%$ & $94.6 \%$ & $100.0 \%$ & \\
\hline & 10 & 89 & 99 & \\
\hline Obese & $10.1 \%$ & $89.9 \%$ & $100.0 \%$ & \\
\hline Hypertension & & & & \\
\hline Yes & 0 & 109 & 109 & \\
\hline Yes & $.0 \%$ & $100.0 \%$ & $100.0 \%$ & 0.00 \\
\hline & 15 & 93 & 108 & 1 \\
\hline No & $13.9 \%$ & $86.1 \%$ & $100.0 \%$ & \\
\hline Smoking & & & & \\
\hline & 11 & 139 & 150 & \\
\hline Ex-smoker & $7.3 \%$ & $92.7 \%$ & $100.0 \%$ & \\
\hline Smol $>$ & 2 & 14 & 16 & 0.46 \\
\hline Smoker & $12.5 \%$ & $87.5 \%$ & $100.0 \%$ & \\
\hline Non smoker & 2 & 49 & 51 & \\
\hline
\end{tabular}




\section{\begin{tabular}{|l|l|l|}
\hline $3.9 \%$ & $96.1 \%$ & $100.0 \%$ \\
\hline
\end{tabular}}

\section{DISCUSSION}

Chronic cholecystitis is mostly caused by repeated attacks of acute (sudden) cholecystitis. Most of the attacks are caused by stones present in the gallbladder. The gallstone diseases are the most common cause of acute abdominal diseases in which patients are admitted to hospital for immediate intervention in the developing countries [12]. They cause the walls of the gallbladder to become thicker leading to shrinkage of the gallbladder. Over time, its ability to concentrate, store, and release bile decreases. Chronic cholecystitis is more common after age 40 and they are more prevalent among women ${ }^{[13,14]}$. The classic patient suffering from chronic cholecystitis is fatty, over 40, fertile, and female ${ }^{[15]}$. According to Khan et al. pregnancy and birth control pills are risk factors of gallstones ${ }^{[16]}$. Our results showed that the prevalence of chronic calculus cholecystitis was $6.9 \%$. This prevalence was slightly lower than that found in another study conducted in KSA where the overall prevalence of gallstones was $11.7 \%{ }^{[17]}$. Also, the average of the prevalence was $4-12 \%$ in Middle Eastern countries ${ }^{[18]}$. On the other hand, the prevalence was higher compared to that reported from different parts in the world as in (Baghdad) $3.3 \%,{ }^{[19]}$ China $(3.2 \%){ }^{[20]}$ and Tiwan $6.12 \%{ }^{[21]}$. In our study, the prevalence of chronic calculus cholecystitis was more in females than males $(9.0 \%$ Vs $4.2 \%)$. Alishi et al. ${ }^{[22]}$ reported that, the female gender showed a significant association with gallstones where $72.1 \%$ of females suffered from gallstones compared with $27.9 \%$ of males and $51 \%$ of females in the control group. Bateson ${ }^{[4]}$, reported that, among 80-89 years British elderly, $28 \%$ of men and $42 \%$ of women have gallstones. Other previous studies were also reported that the disease showed a significant prevalence in females which could be due to the estrogen hormone that would increase the saturation of cholesterol in the bile which in turn enhance the formation of gallstone ${ }^{[23-24]}$. In the current study, gallstones prevalence was $10.1 \%$ in obese, $5.4 \%$ in overweight, $3.6 \%$ in normal and $0 \%$ in underweight. Diabetes mellitus showed significant association with prevalence of gallstones $(\mathrm{P}<0.05)$. Sodhi et $\boldsymbol{a l} .{ }^{[25]}$ reported that patients with type II Diabetes had higher probability of having gallstones compared to the general population. They found also that female sex and higher BMI were independently associated with gallstone disease. Diabetes was also a risk factor for gallstones formation in Alishi et al. ${ }^{[22]}$.

\section{CONCLUSION}

The overall prevalence of gallstone disease among elderly in Arar, KSA was 6.9\%. Female gender, diabetes and obesity are significant factors associated with the formation of the gallstones. Thus, understanding the gallstones pathogenesis would result in life style modifications and weight loss which would decrease the rates of the disease.

\section{CONFLICTS OF INTEREST}

There are no conflicts of interest.

\section{REFERENCES}

1. Chen X, Cai J (2003): The impact of selective cycloxygenase-2 inhibitor celexibo on the formation of cholesterol gallstone. Zhonghua Nei Ke Za Zhi., 42(11): 797-799.

2. Shaffer E (2018): Cholelithiasis - symptoms, diagnosis and treatment. BMJ., 873

3. Burkitt D, Tunstall M (1975): Gallstones: geographical and chronological features. The J Trop Med Hyg., 78:140-144.

4. Bateson MC (1984): Gallbladder disease and cholecystectomy rates are independently variable. Lancet, 2(8403): 621-624.

5. Lu SN, Chang WY, Wang LY et al. (1990): Risk factors for gallstones among Chinese in Taiwan. A community sonographic survey. J. Clin Gastroenterol., 12:542-546.

6. Nomura H, Kashiwagi S, Hayashi J et al. (1988): Prevalence of gallstone disease in a general population of Okinawa, Japan. Am J Epidemiol., 128:598-605.

7. Khuroo MS, Mahajan R, Zargar SA et al. (1989): Prevalence of biliary tract disease in India: a sonographic study in adult population in Kashmir. Gut, 30:201-205.

8. Tamimi TM, Wosomu L, Al Khozaim A et al. (1990): Increased cholecystectomy rates in Saudi Arabia. Lancet, 336:12351237. 
9. Pazzi P, Petroni ML, Prandini $\mathbf{N}$ et al. (2000): Postprandial refilling and turnover: specific gallbladder motor function defects in patients with gallstone recurrence. Eur J Gastroenterol Hepatol., 12(7): 787-94.

10. Lopushinsky S, Urbach D (2005): Gallstone disease in the elderly: diagnosis and management. Future Medicine, 1(3): 440-451.

11. González G, Alvarez S, López G et al. (1997): Gallstone disease in patients over the age of 80. Surgery or long-term medical treatment?. Rev Esp Enferm Dig., 89(3):196-205.

12. Beckingham $I J(2001)$ : $A B C$ of diseases of liver, pancreas, and biliary system. Gallstone disease. BMJ.,322:91-94.

13. Theise ND (2015): Liver and gallbladder. In: Kumar V, Abbas AK, Aster JC, eds. Robbins and Cotran Pathologic Basis of Disease. 9th ed. Philadelphia, PA: Elsevier Saunders.

14. Wang DQH, Afdhal NH (2016): Gallstone disease In: Feldman M, Friedman LS, Brandt LJ, eds. Sleisenger and Fordtran's Gastrointestinal and Liver Disease. 10th ed. Philadelphia, PA: Elsevier Saunders.

15. Jones MW, Ferguson $T$ (2018): Gallbladder, Cholecystitis, Chronic. Available from: https://www.ncbi.nlm. nih.gov/books/NBK470236/

16. Khan MK, Jalil MA, Khan MS (2007): Oral contraceptives in gall stone diseases. Mymensingh Med J. ,16(2):S40-45.

17. Abu-Eshy SA, Mahfouz AA, Badr A et al. (2007): Prevalence and risk factors of gallstone disease in a high altitude Saudi population. Eastern Mediterranean health journal, 13: 794-802.
18. Khalaf SK, Al Mousawi JH, Hussein A et al. (2016): Prevalence and Risk Factors of Asymptomatic Gallstones in a Sample of Population in Basrah, Iraq. Archives of Medicine, 8: 1-6.

19. Al-Obaidi SM, Abdulla TS, Al-Alawi MS et al. (2006): The prevalence of silent gallstones and its relation to some risk factors in Iraq. The Iraqi postgraduate medical Journal, 5: 146-150.

20. Xu Q, Tao L-y, Wu Q, Gao F et al. (2012): Prevalences of and risk factors for biliary stones and gallbladder polyps in a large Chinese population. HPB., 14: 373-381.

21. Chen YC, Chiou C, Lin MN et al. (2014): The prevalence and risk factors for gallstone disease in taiwanese vegetarians. PloS one, 9: 115-145.

22. Alishi YA, Howaish FA, Alhamdan FA et al. (2017): Prevalence and Risk Factors for Gallstones among Population in Riyadh City, KSA 2017. The Egyptian Journal of Hospital Medicine, 69 (5):2384-2388

23. Panpimanmas S, Manmee C (2009): Risk factors for gallstone disease in a Thai population. Journal of epidemiology / Japan Epidemiological Association, 19: 116-121.

24. Novacek G (2006): Gender and gallstone disease. Wiener medizinische Wochenschrift, 156: 527-533.

25. Sodhi JS, Zargar SA, Khateeb S et al. (2014): Prevalence of gallstone disease in patients with type 2 diabetes and the risk factors in North Indian population: a case control study. Indian journal of gastroenterology : official journal of the Indian Society of Gastroenterology, 33: 507-511. 